\title{
PERFORMANCE COM BEBÊS: DEITAR E ROLAR.
}

Fernanda Paixão ${ }^{\mathrm{i}}$

\begin{abstract}
RESUMO: Este texto é um relato de experiência da prática performativa que realizei no âmbito de minha pesquisa de mestrado na Universidade Federal do Estado do Rio de Janeiro com um grupo de adultos e bebês. A prática abordou os aspectos relacionais da linguagem da performance e os desafios da comunicação inter-geracional, verbal e pré-verbal.
\end{abstract}

Palavras-chaves: infância; performance; programa performativo; relação; bebês.

\section{PERFORMANCE WITH BABIES: REST AND ROLL}

\begin{abstract}
This paper is an experience report of the performative practice that I carried out as part of my master's research at the Federal University of Rio de Janeiro with a group of adults and babies. The practice addressed the relational aspects of performance language and the challenges of intergenerational, verbal and pre-verbal communication.
\end{abstract}

Keywords: childhood, performance art, performative program, relationship, babies.

Este relato traz reflexões acerca da minha pesquisa de mestrado em performance. Escolhi seguir um projeto de pesquisa-criação na qual a prática inspira a escrita e vice-versa. A abordagem que venho elaborando traz à tona o aspecto relacional da performance. Para desenvolver algumas reflexões acerca deste aspecto, propus um espaço de convivência entre bebês e adultos na Universidade. Chamei este espaço de Encontro Performance, o encontro evidenciou os desafios da comunicação intergeracional, verbal e pré-verbal.

Papagaio, dinossauro e tucano de tecido, um polvo de madeira, xequerê, palha dentro de filó, instrumentos feito com tampinhas de plástico, luvas de pano para limpar casa, leque com plumas, uma máscara do personagem da commedia dell arte Pantalone, uma garrafinha com fitas do Senhor do Bonfim dentro, diabolô e tubos de borracha colorida entrelaçando todos os objetos no meu corpo. aberto distribuído sob os termos da Licença Creative Commons Atribuição Não ComercialCompartilha Igual (CC BY-NC-4.0), que permite uso, distribuição e reprodução para fins não comerciais, com a citação dos autores e da fonte original e sob a mesma licença 


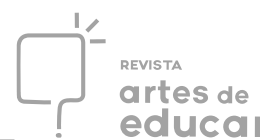

Me programei para estar com esses objetos entrelaçados no meu corpo, em uma das salas da Universidade transformada em espaço de convivência para os encontros com bebês e adultos de diversos lugares do Rio de Janeiro. Na Universidade, foram realizados três encontros, a divulgação foi feita em redes sociais. Fez parte do roteiro das minhas ações, não verbalizar e fazer somente cinco movimentos por uma ou duas horas de duração: deitar, rolar, rastejar, engatinhar, sentar e em algum momento chegar a ficar de pé e assim caminhar, saindo de um estado de silêncio e vínculo, que vou chamar de "estado performativo", com os bebês e adultos presentes.

No inicio do encontro ou quando os convidados chegavam, adultos e bebês entravam no espaço e cada adulto era convidado a sortear uma mensagem escrita em um origami de tsuru. No total, havia cinco mensagens para serem sorteadas: Qual é a distância que o bebê pode e consegue ficar de você? / Quanto tempo você consegue não conduzir o bebêe? / Perceba como o bebê explora os objetos e explore também. / Quanto tempo você consegue ficar sem verbalizar? I Qual movimento o bebê mais gosta de fazer? Faça também.

Após esse momento, os participantes se acomodavam no espaço como quisessem. Ao fundo, um som de água pingando, havia algumas percussões de mão espalhadas pelo espaço e o piano da sala estava aberto. Em alguns momentos um dos pais tocou piano, com seu filho no colo, ressoou na sala algumas notas esparsas.

Os objetos, o som e as ações eram parte de um "programa performativo", construído por mim, a fim de suscitar reflexões acerca da performance relacional, da infância e da existência como uma jornada rumo a acontecimentos que não ainda não conhecemos. A expressão "programa performativo" foi elaborada pela pesquisadora e performer Eleonora Fabião ao refletir sobre a construção de performance, influenciada pelos filósofos Gilles Deleuze e Félix Guattari. Segundo Fabião (2013, p. 4), “o programa é o enunciado da performance: um conjunto de ações previamente estipuladas, claramente articuladas e conceitualmente polidas a ser realizado pelo artista, pelo público ou por ambos sem ensaio prévio".

Os escritos e as performances de Eleonora me inspiram há alguns anos, mas após a realização desse programa, que descrevi acima, com os bebês e adultos em um encontro intergeracional, pude entender quando ela diz que ao realizar um programa o performer suspende automatismos (...) desprograma a si e ao meio (FABIÃO, 2013 p.5). Não penso em me precipitar definindo quais mudanças a performance que venho realizando com bebês gera no 
mundo e sim me ater aos automatismos que pude suspender em mim, que ao mesmo tempo são hábitos, costumes de uma sociedade da qual estou inserida. Assim, me relaciono com o meio ambiente pelo meu corpo que é cultural e parte de uma complexidade de realidades sociais.

\section{DEITAR, ROLAR, RASTEJAR, ENGATINHAR, SENTAR}

Figura 1 - Sala Nelly Laport, Universidade Federal do Estado do Rio de Janeiro.

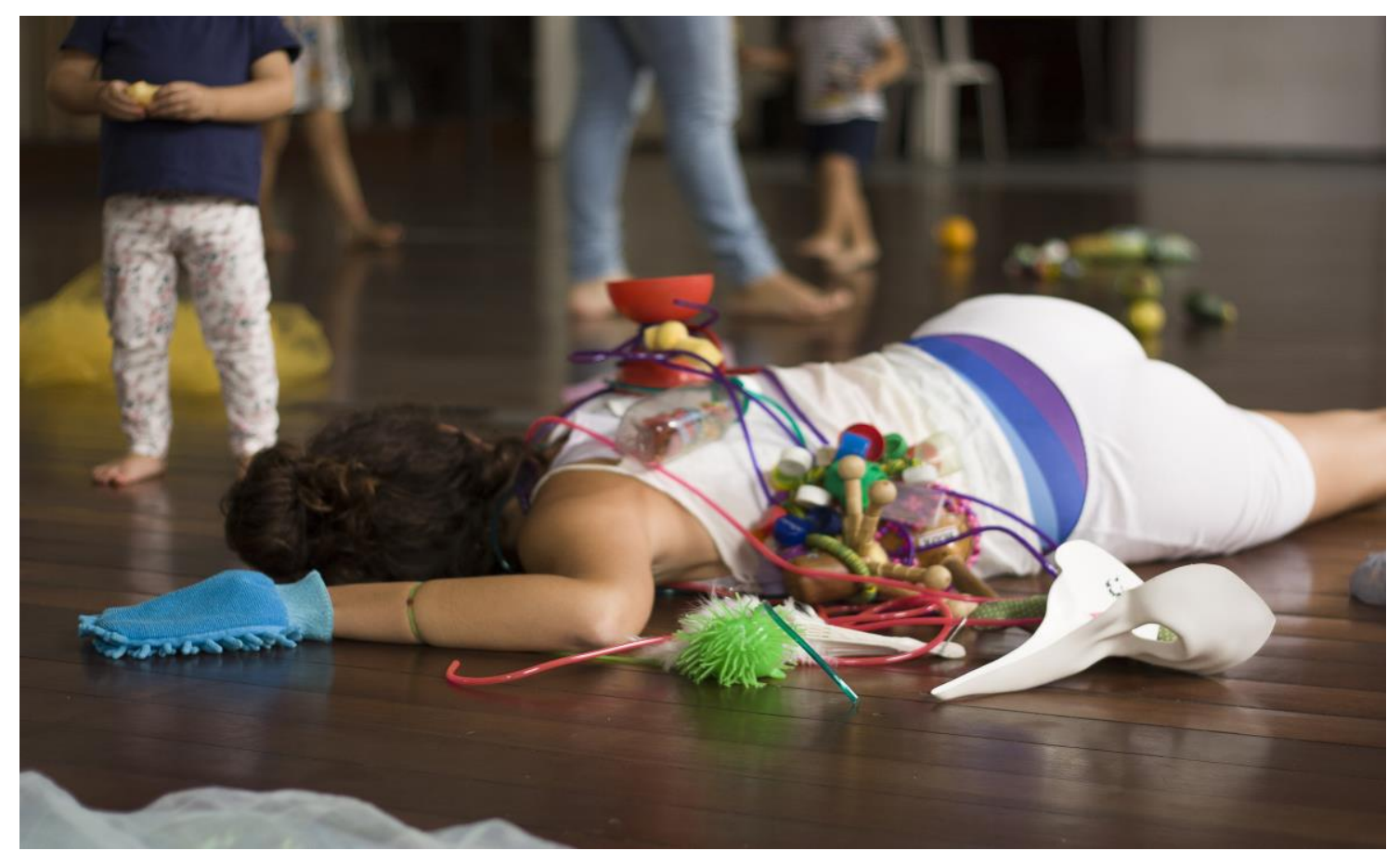

Foto: Joanna Balabram ${ }^{\mathrm{ii}}$.

Figura 2 - Sala Nelly Laport, Universidade Federal do Estado do Rio de Janeiro.

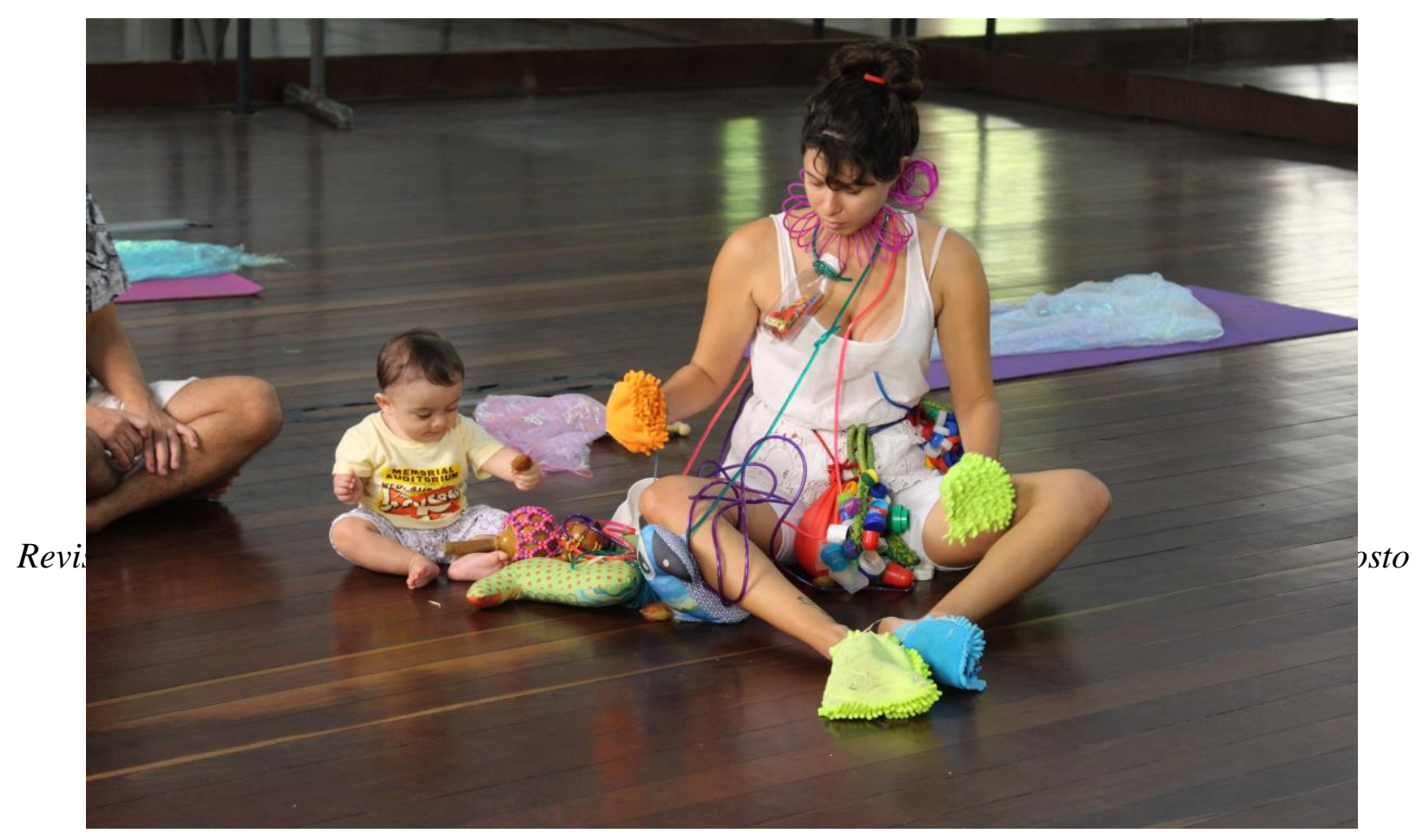


Foto: Ana Raquel Machado.

Figura 3 sala Nelly Laport, Universidade Federal do Estado do Rio de Janeiro.

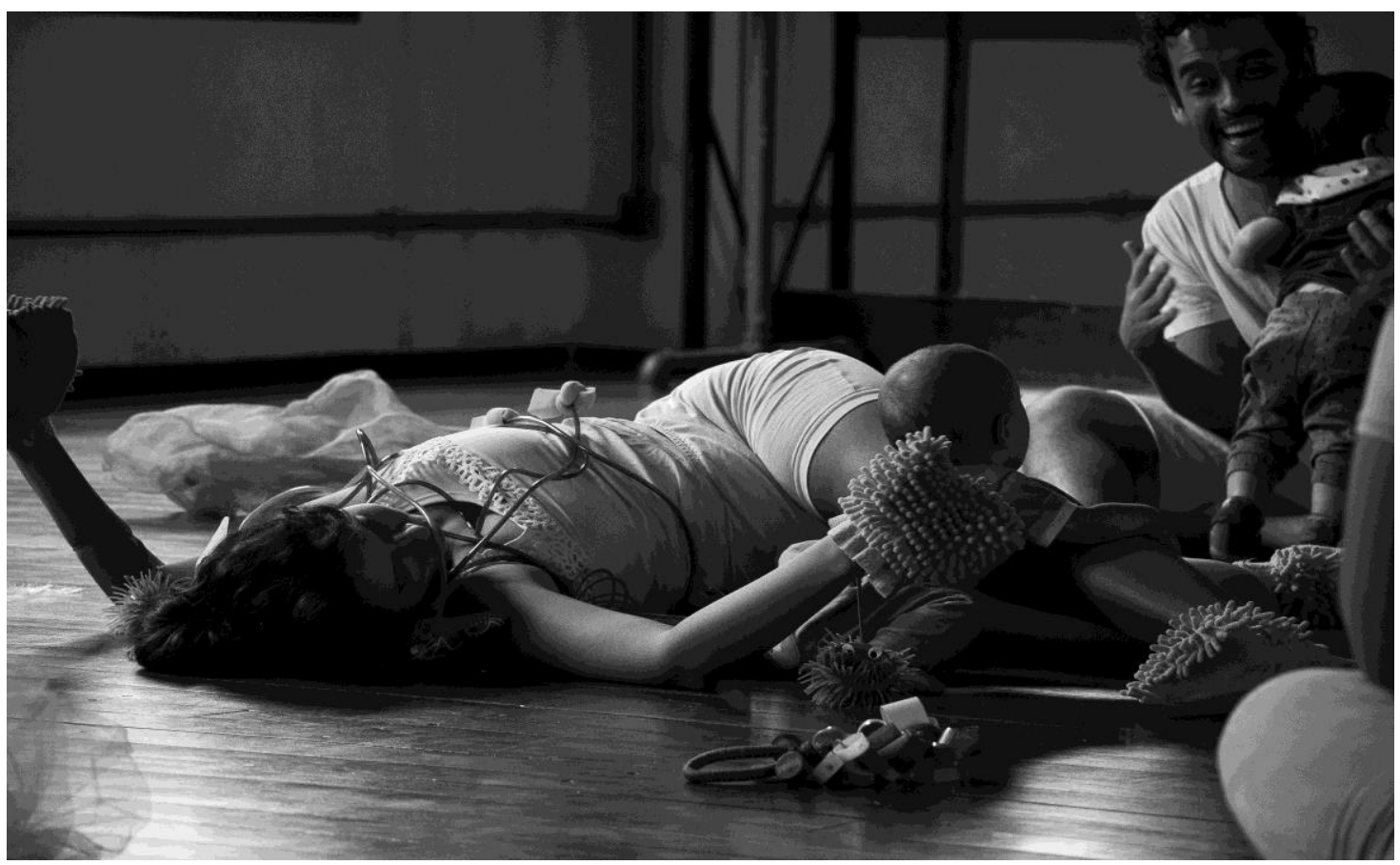

Foto: Joanna Balabram.

Estas ações foram decididas quando eu mudei minha perspectiva relacional com esses participantes da primeiríssima infância: queria construir uma performance com bebês e não para eles. Após essa constatação, minha primeira decisão foi abaixar-me e diminuir a distância espacial que existe entre o corpo de uma adulta e dos bebês. Essa atitude me fez pensar em como cheguei a caminhar. Para desenvolver essa reflexão, eu precisei buscar auxílio de práticas corporais que nos conduzem a essas respostas ou a essa pergunta.

Atualmente, no Brasil, alguns pesquisadores em dança participam do programa de estudos Body Mind Centering - BMC iii, desenvolvido pela pesquisadora e educadora estadunidense Bonnie Bainbridge Cohen. Eu pude entrar em contato com esse estudo por meio das aulas oferecidas pelas pesquisadoras e coreógrafas Andrea Jabor, Dani Lima e Maria Elvira Machado no Rio de Janeiro.

Em alguns encontros, Andrea, Dani e Maria propuseram essa sequência de ações que fazem parte do nosso desenvolvimento inicial - deitar, rastejar, rolar, engatinhar e sentar. Pude perceber que o meu movimento de engatinhar não estava internalizado, ao invés de fazê-lo cruzado, eu o fazia homo lateralmente. Investiguei com meus familiares meu histórico nesse 
tenro desenvolvimento e descobri que quase não experimentei esse estágio do engatinhar. Continuei a busca à pergunta inicial com ajuda de alguns autores como o psicólogo Stanley Keleman. Segundo este autor: "o engatinhar é o primeiro momento em que começamos a superar a impotência. O engatinhamento também libera a cabeça para sondar o ambiente estimulando uma organização do espaço que nos leva a sentar”. (KELEMAN, 1992, p.36).

Na performance, eu voltei ao estado do engatinhamento e pude sondar o ambiente junto aos bebês que participaram dos encontros; esse deslocamento de alturas e percepções me coloca em uma não hierarquia de saberes. Eu estava dentro de uma instituição de ensino superior, como aluna da Pós-Graduação, aprendendo a engatinhar com seres humanos que ainda não falam, muito menos leem e escrevem. Estar em pé traz em si uma sucessão de movimentos iniciados no engatinhar e até no nascer, vir ao mundo. De acordo com essas sucessões, nós podemos perceber a complexidade de estar em pé, pois alcançamos uma maior independência de locomoção do que ao engatinhar, mas nunca de forma onipotente e sim com uma interdependência relacional. Não podemos ir e vir pelas ruas sem considerar as leis, as casas, os espaços públicos e privados, as sensações de segurança, os encontros e desencontros.

Há três padrões que nos levam da motilidade animal ao movimento humano, à postura ereta e ao caminhar: buscar, trazer e caminhar [...] aprender a ficar em pé envolve um domínio ainda maior de uma outra sucessão de movimentos, que vão do rastejar ao engatinhar, ao acocorar com os braços estendidos; fazer força para cima, depois levantar e, finalmente, ficar em pé sozinho. (KELEMAN, 1992, p.11; 32-33)

Stanley Keleman ao estudar as sucessões físicas do desenvolvimento humano também traz à luz as marcas do amor e da decepção: "do ponto de vista do processo, a vida é uma sucessão de formas, que se movem mais ou menos como num filme (...) a forma humana é marcada pelo amor e pelas decepções" (KELEMAN, 1992, p.11). Se estamos marcados pelos sentimentos e afetações, não somos senhores de nós mesmos por conseguirmos caminhar, as emoções estão, muitas vezes, relacionadas às relações com o outro e portanto sempre em constante impermanência.

Como artista tenho me interessado cada vez mais pelos espaços de convivência que a arte pode proporcionar e pelas conexões afetivas que se evidenciam nesses espaços. O bebê, que está diante de nós, é uma pessoa que produz sentidos para o mundo, constrói bases e inicia sucessões 
de movimentos e afetos que o colocam em relação consigo mesmo e com o outro que está diante dele, mas também serão constituintes do ser adulto no futuro.

Por eles estarem aprendendo a língua portuguesa e não conseguirem verbalizar o que querem ou estão sentindo, muitas vezes estabelecemos uma relação de condução do seu olhar, dos seus movimentos, sem perceber o tempo próprio do bebê de descobertas e interesses. Além disso, nós estabelecemos uma dinâmica de aprovação e não aprovação dos movimentos do bebê constante. Anna Tardos, psicóloga húngara dedicada ao desenvolvimento infantil reflete sobre alguns desses hábitos em atividades dirigidas pelos adultos para as crianças que considero relevante para o trabalho com os bebês:

Os adultos, em geral, e professoras e educadoras, em especial, desejam obter de forma imediata resultados espetaculares concretos. Por isso, querem terminar o desenho planejado, mesmo que guiando a mão da criança. É por isso, que gostam de dar diretrizes, passo a passo, já que assim tornarão o desenho da bola, da gota d'água, do muro, em resultados visíveis da atividade. O resultado fica mais importante do que a criança. (TARDOS, 2010. p.82)

Neste sentido, começo a relatar aqui as suspensões dos automatismos relacionais que vinha estabelecendo com bebês. Todas as questões suscitadas nesta pesquisa referente à infância são pensadas por meio da linguagem da performance, trago portanto, como disparador das reflexões, o programa performativo e sua potente desprogramação de automatismos próprios que são, ao mesmo tempo, sociais.

Em raros momentos emiti alguns sons, inspirada nas vocalizações dos próprios bebês. Os adultos participantes ficam livres para verbalizar ou não. Eu escolhi essa forma de comunicação para, assim como os movimentos que faço, me aproximar da forma de estar no espaço dos bebês e vivenciar esta forma de presença. $O$ fato de não verbalizar contribuiu de forma contundente a essas suspensões, com a fala eu poderia expressar rapidamente o que desejo, no entanto o tempo de quem não está verbalizando é diferente. Desta forma, eu era impelida a perceber no meu corpo impulsos e vontades sem formular rápidas resoluções verbais.

Não pretendo com este trabalho propor um tipo de relacionamento entre adultos e bebês sem verbalização, essa forma é somente uma escolha momentânea, dentre muitas outras escolhas possíveis. Ao longo do processo de construção dessa performance pude ver o documentário "Iniciativa, Cooperação e Reciprocidade" feito por Éva Kálló e Julianna Vámos, que mostra as cuidadoras do Instituto Pikler-Lóczy ${ }^{\text {iv }}$ descrevendo verbalmente as ações a serem realizadas com 
o corpo do bebê antes de fazê-las. Após falar com ele, era recomendado perceber se o corpo do bebê evidenciaria alguma resistência ao movimento do adulto. Nesse caso, a verbalização era uma escolha para a relação entre adultos e bebês.

Essa performance traz à tona o aspecto relacional para todas as idades, portanto o encontro intergeracional me brindou possibilidades lúdicas e não cotidianas de experimentar presença, escuta e vínculo. Isso! Muito Bem! Olha aqui! Aqui! Eeee!! Palmas! Sacolejar de objetos a fim de chamar atenção do bebê, pegar no colo, levar de um ponto a outro do espaço com o intuito de mostrar algo, foram expressões e hábitos muito comuns dos adultos que pude notar nos encontros com os bebês. Enquanto isso eu rastejava, sentava, rolava, deitava, engatinhava, trocando olhares e alguns sorrisos com as crianças. Em muitos momentos queria dizer: - aqui!! Eu estou Aqui! Olha todos esses objetos que coloquei no meu corpo! Esse instrumento tem barulho de água, olha!! No entanto, não pude. Precisei silenciar estas vontades em mim, descobrindo um outro modo de me relacionar.

Os bebês me notavam, às vezes chegavam perto, durante muito tempo olhavam de longe, tinham medo, se sentiam atraídos, tocavam bem de leve os objetos e em muitos momentos eu ficava no espaço sem estabelecer um contato direto com eles, meu corpo estava pulsando sem aprovação, sem uma atenção dada e nem solicitada.

O encontro terminava quando eu levantava e ia arrumando as coisas da sala. Nesse momento, muitos pais vinham falar algo, agradecer, perguntar, outros não diziam nada e o aplauso, comum no teatro, não tinha espaço, nem fazia sentido. Em um dos encontros, um adulto me perguntou: qual o sentido da performance? E disse que me perguntava isso, porque falar é importante para o desenvolvimento da criança, comentou também que não sabia se era pra ele falar ou ficar quieto, mas que acabou falando um pouco. Eu respondi que não era nem pra falar, nem pra ficar quieto. Eu como performer não falo nesse encontro, mas não digo como os outros devem se comportar. No espaço da UNIRIO, como lugar de pesquisa, os pais relatavam desafios e pediam meu contato para ler a dissertação no final, artistas-pesquisadores também foram assistir e conversamos sobre o trabalho depois.

Ao retirar a fala de quem é o propositor da experiência, é possível rever o hábito de condução, se é necessário conduzir e consequentemente aprovar. Quando direcionamos algo, nós temos em mente algum ponto de chegada e então, observamos se o bebê segue conforme pensamos essa trajetória ou não. Em um dos dias, na UNIRIO, veio uma criança de quatro anos, 
acompanhando seu irmão bebê na experiência, para ela foi bastante desafiante, ela corria pelo espaço e gritava: como eu brinco? E eu ali, adulta, rastejando, engatinhando, rolando, deitando sem direcionar nada a ela e nem ao menos falar algo que a conforte.

Eu pensei em falar para ela ficar no espaço, olhar, ver e que ela podia tocar, se quisesse, nos objetos, que a sala era grande e tive vontade também de até cantar uma música conhecida e fazer ritmos com o xerquerê, mas eu não podia, não era disso que se tratava o programa performativo.

Eu estava programada e ao mesmo tempo desprogramando essa "programação" de dizer como a criança deve brincar que existe na relação entre adulto e criança na maior parte do tempo, seja na escola, em casa e nas atividades artísticas. Quando não dizemos como a criança deve brincar, damos a oportunidade de ela perceber como ela vai brincar e assim aprender a pensar, a construir seu mundo. Em nenhum momento defenderei nesta pesquisa que não podemos mostrar algo, fazer alguma atividade para o bebê, porém é do interesse desta pesquisa suspender as possibilidades de comunicação habituais entre aquele que já viu, já conhece e aquele que está descobrindo.

Anna Tardos fala em seu artigo "Autonomia e/ou dependência" que o bebê:

quando deitado na sua cama, ele contempla ao seu redor em silêncio, mexe suas pernas, por uns instantes seu olhar se volta para seu punho; ou quando justamente está ocupado com seu lencinho, com a ponta do cobertor que se enrosca em sua mão. O adulto vai até a criança, distraindo a sua atenção, faz com que cesse de imediato o processo de atividade iniciada por ela e desvia seu interesse. ( TARDOS, 2010, p.60)

Esse espaço de livre exploração da performer e dos participantes tem uma preparação anterior: visando a segurança da experiência, tomadas, pregos, farpas, são retirados ou tapados; os objetos não podiam ser muito pequenos, nem cortantes. Cada objeto foi escolhido pelo critério de cores contrastantes, texturas e formas diferentes, alguns eu ganhei, como a garrafinha com fitas coloridas do Senhor do Bonfim. Apesar de não ser devota quis acoplar ao meu corpo, são objetos que também fazem parte da minha trajetória de alguma forma.

Entre engatinhar e escrever existe a corporalização do pensamento. Corporalizar no dicionário Houaiss online é definido como "dar corpo a; materializar. Tornar palpável, patente, evidente". Corporalizar este pensamento acerca da performance relacional com bebês detonou 
outros entendimentos que somente via as ações corporais eu pude perceber, entender. Para Bonnie Cohen corporalização é:

\begin{abstract}
a consciência da célula sobre si mesmas. Você abandona seu mapeamento consciente. É uma experiência direta; não há passos intermediários nem mudanças. Não há guia nem testemunha. Há uma consciência muito conhecida do momento experimentado iniciado nas próprias células. Nesse caso, o cérebro é o último a saber. Há um conhecimento completo. Há um entendimento tranquilo. Desse processo de corporalização surge sentimento, pensamento, testemunho, compreensão (...). (COHEN, 2015, p.279)
\end{abstract}

As cinco ações feitas por mim têm a função de possibilitar um entendimento mais completo da experiência relacional e uma percepção mais aguda do meu corpo diante do outro, com o outro. A primeira das cinco ações é deitar, eu deitava com as costas no chão, os braços estendidos ao lado do corpo. Essa forma de deitar é conhecida na Yoga como Shavassana (a postura do descanso), mas eu ficava de olhos abertos, deixando o peso do meu corpo no chão antes de qualquer participante do encontro entrar, quando eles entravam eu já estava nessa posição. O tempo em que me movia e olhava para alguém sempre dependia de cada dia. Angel Vianna nos fala sobre o ato de deitar, em uma entrevista concedida à Ana Vitória Freire : “ - só a colocação dos meus apoios no espaço já me traz uma consciência maior e sou capaz de confiar no meu corpo e me entregar para a experiência de viver. Descobrir as maneiras de trabalhar o corpo, não ficar só em uma forma, é radical...” (FREIRE, 2018, p. 226)

Essa entrega inicial foi imprescindível para que eu abrisse espaço na minha mente e no meu corpo para trabalhar em performance com bebês e me relacionar com elas de outra forma. Eu sempre trabalhei como arte educadora em projetos para crianças - não tanto com bebês, oferecendo oficinas de arte a elas. Considero que tenho uma prática de escuta cada vez mais ampla com a criança, mas como diz Angel - "não ficar só em uma forma é radical”. O vínculo, a atenção, o entendimento sobre mim e sobre elas se evidenciaram de uma forma mais profunda.

Em cada aula, eu sempre tinha um "objetivo", um conteúdo, alguma experiência para proporcionar que atendesse às demandas do currículo ou ementa do projeto pedagógico ao qual eu estava inserida. $\mathrm{Na}$ performance, existe um programa performativo que inclui certos movimentos, objetos e uma sonoridade. Na relação com o bebê esses objetivos podem tomar protagonismo assim como com a criança. Percebo que a proposta relacional realizada em performance amplia minha escuta com pessoas de todas as idades

Revista Interinstitucional Artes de Educar. Rio de Janeiro, V. 6, N.2- pág. 735-748 maio-agosto de 2020: "Bebês e crianças: cultura, linguagem e políticas"

DOI: 10.12957/riae.2020.44803 


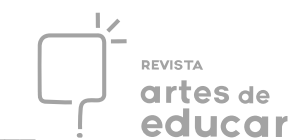

A sonoridade da performance é inspirada na água intrauterina, com o objetivo de confortar o bebê e trazer um aspecto de fluidez para corpo de todos, a fluidez é intrínseca ao elemento água. Estes estímulos se constituem como uma estrutura, uma base para o encontro. $\mathrm{Eu}$, como propositora, não tenho algum produto a ser construído com os participantes, assim o motivo da performance é o encontro em si.

$\mathrm{O}$ aspecto relacional desse programa performativo se dava sempre entre adultos e bebês, pois os adultos participantes ficavam na posição também de cuidadores dos pequenos, ao menos para levá-los até o espaço, às vezes um ou outro bebê corria para o banheiro e então os pais fechavam a porta. Às vezes algum bebê se angustiava muito e necessitava do colo da mãe, do pai ou de alguém que estivesse cumprindo essa função. Eu me relacionava com todos eles, em silêncio e fazendo os cinco movimentos.

Os dois maiores desafios relacionais para mim foi lidar com as expectativas e com a necessidade de aprovação do meu trabalho por parte dos participantes. Muitas vezes os bebês ficavam muito tempo sem "me notar" e isso era angustiante, eu pensava: "Minha figura está aqui, extremamente chamativa, eles não vão vir até mim?"

No primeiro encontro, o $\mathrm{Bem}^{\mathrm{v}}$ de sete meses foi o primeiro a chegar. Ele ficou por volta de vinte minutos perto da porta de entrada segurando um plástico bolha que estava no chão ( o plástico bolha foi retirado dos encontros seguintes para diminuir a quantidade de plástico), eu estava ansiosa para que ele se aproximasse, os pais também estavam ansiosos, até que em algum momento a mãe colocou ele do meu lado.

Depois a mãe do Bem me disse que havia sorteado a pergunta - Quanto tempo você consegue não conduzir o bebê? E por isso, conseguiu mantê-lo um tempo ali, no plástico bolha. Ela estendeu o tempo de sua pressa em conduzi-lo, mas em algum momento chegou ao seu limite e levou ele para perto de mim. Quando o Bem estava ao meu lado, trocamos olhares durante muito tempo e depois ele pegou no instrumento que fazia som de água, no restante do tempo era meu short branco que chamava mais a sua atenção. Em todos os encontros, os bebês ficavam mais de uma hora experimentando seus movimentos no espaço e o manuseio dos objetos, totalmente presentes na enorme sala de chão de madeira, imersos em suas investigações que eu não podia entender, somente divagar sobre possibilidades do que eles poderiam estar sentindo.

Revista Interinstitucional Artes de Educar. Rio de Janeiro, V. 6, N.2-pág. 735-748 maio-agosto de 2020: "Bebês e crianças: cultura, linguagem e políticas" 
Após a aproximação de Bem, eu comecei a brincar com os objetos e a relacionar-me com eles como eu queria que o bebê fizesse, elas nunca fizeram como eu fazia, mas estavam ali, brincando com o que queriam e eu com o que eu queria. Após estas batalhas internas, minha atenção estava ora imersa nos meus desejos e trocas de olhar com os bebês, movimentos feitos a partir do que eles puxavam em mim, ora em uma certa preocupação em fazer algo para conduzir os bebês, porém eu me desacostumei a essa prática de condução e mantive os cinco movimentos em silêncio.

Nesta experiência vou ao encontro também da performance. A linguagem vai se apresentando para mim, mesmo que sem uma definição rígida. A performer e pesquisadora franco-brasileira Tania Alice ressalta a importância de não perseguirmos uma definição essencialista do que é performance e sim o que "vem sendo" performance:

[...] podemos entender a linguagem da performance: como uma linguagem que não constitui apenas uma representação de determinada situação ou contexto, mas que, realizando e efetuando-se, modifica o presente, influi ativamente nele, propondo transformações nos modelos de poder vigente, remodelando as subjetividades e as relações previamente estabelecidas. É nessa transformação que podemos ver a potência principal da performance: a performance não representa, mas é, transforma, recria, remodela modelos vigentes, tornando visível e palpável o invisível e o despercebido, e propõe alternativas para a transformação. (ALICE, 2016, p.23)

Penso que ao fazer os movimentos do desenvolvimento da criança, eu vivi o limiar entre ser e representar, pois eu não preciso engatinhar mais como adulta. Se pensarmos que representar é poder ver o mundo com o ponto de vista de outros, diferente de você, podemos pensar que a representação influencia o programa performativo que realizei. O meu estado interno, assim como os desafios que esses movimentos me causam, me faz ser de outra forma, por outro lado é bastante distante do modo de representação em que construímos um personagem; sou eu, Fernanda, agindo de outra forma com a mesma identidade. Pode ser possível representar em performance? Penso que é possível ao menos colocar em jogo a representatividade.

No caso do Encontro Performance, eu descubro, ao longo da ação, um estado de vir a ser criança, vir a ser mim mesma, de vir a ser mãe, pai, cuidadora. Tudo é um "vir a ser", pois esses estados não se estabelecem como forma definida, mas sim como forma sempre mutante. São todos esses modos de existir que habitam o meu corpo em relação com os participantes e o espaço. O que é vigente em mim mesma se transforma. O filósofo moçambicano José Gil traz 
em seu texto "A reversão" algumas reflexões sobre um devir na criança que se aproxima do que experienciei nesse estado performativo.

Uma criança brinca com um avião. Pega nele, descola, desliza no ar, dá-lhe uma aceleração depois abranda, depois vira-o em um looping arrojado, aterra, descola outra vez. Acompanha o movimento do avião, o ruído dos seus motores que marcam a velocidade, as diferenças. Há um devir-avião da criança. Nesse devir-avião surgem e sucedem-se fenômenos complexos: o avião adquire vida, uma anima, o avião sente, o seu movimento modula afectos e emoções, de tal maneira que a criança fala com ele e fá-lo responder-lhe. (GIL, 2009, p.19)

O filósofo traz para a vivência da criança a noção de devir de Gilles Deleuze e Felix

Guatarri. Aqui nessa experiência estou em relação com o bebê que ainda não explora a brincadeira com a complexidade apresentada pelo filósofo, porém o vir a ser que eu, performer, pude experimentar se aproxima deste devir da criança. Eu não tinha como objetivo ocupar o lugar de bebê com sentimentos de alegria, rejeição, confusão, mas sim vivenciar tudo isso naquele momento e estando em looping nos movimentos de engatinhar, rolar, sentar, deitar. Esse looping colaborou para que eu fosse adentrando a sensação de estar como bebê.

Em busca de reflexões sobre o que pode ser esse estado performativo, venho dialogando com o conceito de infancialização, elaborado pelos filósofos brasileiros Renato Nogueira e Marcos Barreto que clareia o que tenho descoberto com as rupturas que o processo performativo traz para a pesquisa: "infancializar é uma maneira de perceber na infância as condições de possibilidade de invenção de novos modos de vida" (NOGUEIRA e BARRETO, 2018, p.627).

Engatinhar, sentar, rastejar, deitar e rolar foram os enunciados que elaborei para este programa performativo e por onde pude vislumbrar modos de vida e de relação em que as estruturas de condução e controle são aos poucos eliminadas, abrindo espaço para o desconhecido de si e do outro.

Estar em aproximação com um possível devir bebê ou uma infancialização do meu ser contribui para que eu pudesse experimentar o sentimento de alteridade de forma mais corporalizada. Assim, os trabalhos de educação e arte com bebês, crianças, adultos, podem se tornar um espaço de real escuta e aceitação do outro. Podemos abrir espaço para suas e nossas potencialidades e então o corpo do outro constrói conosco uma sucessão de forças que compõem realidades.

Revista Interinstitucional Artes de Educar. Rio de Janeiro, V. 6, N.2- pág. 735-748 maio-agosto de 2020: "Bebês e crianças: cultura, linguagem e políticas"

DOI: 10.12957/riae.2020.44803 


\section{REFERÊNCIAS}

ALICE, T. Performance como revolução dos afetos. São Paulo: Annablume, 2016.

COHEN, B. B. Sentir, perceber e agir: educação somática pelo método Body-Mind

Centering. São Paulo: Edições Sesc São Paulo, 2015.

FABIÃO, E. Programa Performativo: o corpo-em-experiência. São Paulo: Revista do Lume, n.4, 2013, P. 1-11.

FREIRE, A. V. F. Angel Vianna da expressão corporal aos jogos corporais e a conscientização do movimento na dança contemporânea. Salvador: Revista Repertório, ano 21, n.31, 2018, , p. 214-235.

GIL, J. A reversão. In: LINS, D. (Org.). O devir criança do pensamento. Rio de Janeiro: Forense Universitária. 1 edição, 2009, p. 19-33.

HOUAISS, A. e Villar, M. de S. Dicionário Houaiss da língua portuguesa online. Disponível em: https://houaiss.uol.com.br/pub/apps/www/v3-3/html/index.php\#0 . Acesso em: Jun/2019.

KELEMAN, S.. Anatomia Emocional. São paulo: Summus, 1992.

NOGUERA, R. e BARRETO, M. Infancialização, ubuntu e teko porã: elementos gerais para educação e ética afroperspectivistas. Rio de Janeiro: childhood \& philosophy, v. 14, n. 31, set.dez. 2018, pp. 625-644

TARDOS, A. Autonomia e/ou dependência. In: FALK, Judit (org.). Abordagem Pikler: educação infantil. São Paulo: omniscência, 2016, p. 50-59.

VÍDEO: INICIATIVA, Cooperação e Reciprocidade: o tempo do bebê. Direção: Éva Kálló e Julianna Vámos. Realizado por Pikler-Lóczy Association Hungary, 2017. 1 DVD 38 minutos. NTSC colorido. Título original: Initiative, cooperation and reciprocity: the baby's time.

\footnotetext{
i Fernanda Paixão é artista, mestranda na Universidade Federal do Estado do Rio de Janeiro - UNIRIO, recebe bolsa CAPES para auxílio à pesquisa e integra o grupo de pesquisa Práticas Performativas Contemporâneas com orientação da Prof. Dra Tania Alice. Formação: Licenciatura em Artes Cênicas (UNIRIO), email: fpamoreira@gmail.com, Rio de Janeiro - RJ. ORCID: https://orcid.org/0000-0003-2635-4918

ii Todos os participantes autorizaram as fotos e estão cientes da pesquisa.

iii É uma abordagem de estudo do movimento, da consciência e do corpo baseada na anatomia humana, utilizando toque, voz, movimento e mente. (ver em https://www.bodymindcentering.com/about/ )

iv Um orfanato criado pela pediatra Austríaca Emmi Pikler em Budapesta depois da Segunda Guerra Mundial. Fonte: https://www.piklerloczy.org/es/emmi-pikler-y-el-instituto-1\%C3\%B3czy . Este documentário foi assistido no curso Diálogos com Emmi Pikler com as professoras Cláudia Leão e Eleonora Filgueiras.
}

Revista Interinstitucional Artes de Educar. Rio de Janeiro, V. 6, N.2-pág. 735-748 maio-agosto de 2020: "Bebês e crianças: cultura, linguagem e politicas" 
v Bem é o nome do bebê participante do Encontro na Sala Nelly Laport - UNIRIO.

Revista Interinstitucional Artes de Educar. Rio de Janeiro, V. 6, N.2- pág. 735-748 maio-agosto de 2020: "Bebês e crianças: cultura, linguagem e politicas"

DOI: 10.12957/riae.2020.44803 